\title{
Assessing predictive capability of neuronal network models by computing Lyapunov exponents
}

\author{
Bruno Maranhao ${ }^{1}$, Marius Buibas ${ }^{1}$, Gabriel Silva ${ }^{1,2,3^{*}}$ \\ From Twentieth Annual Computational Neuroscience Meeting: CNS*2011 \\ Stockholm, Sweden. 23-28 July 2011
}

Mathematical models of biology are largely based on systems of nonlinear differential equations that are discretized to facilitate solving. In particular, models of neuronal networks need to incorporate delays between the transmission of information of one state variable to another in the system of equations. In reality delays exists in all physical entities, however; their magnitude relative to the time step needed to simulate the entity may be negligibly small.

We quantitatively assessed the effect that delays in a system of nonlinear difference equations have on the accuracy of modeling neural networks by computing the Lyapunov exponents for systems of equations describing networks that are part of a previously published test set [1]. This is significant because it represents an objective metric of the ability of a model to represent the physical system being modeled. The maximal Lyapunov exponent is a measure of the exponential divergence over time of a pair of initially infinitesimally close points. Even if instruments existed to assess all the variables of a system with $100 \%$ fidelity the limited precision of computers in representing numbers would create small errors between the actual conditions of the system being modeled, and the starting conditions in a computational model. Therefore, all models of the real world that contain positive Lyapunov exponents have a limited predictive capability. Necessary computer code to accomplish this has been written for parallel processing on general purpose graphics processing units to accelerate computational time.

\section{Author details}

'Department of Bioengineering, University of California, San Diego, La Jolla CA 92093, USA. ²Department of Ophthalmology, University of California, San Diego, La Jolla CA 92037, USA. ${ }^{3}$ Neurosciences Graduate Program, University of California, San Diego, La Jolla CA 92093, USA.

\footnotetext{
* Correspondence: gsilva@ucsd.edu

'Department of Bioengineering, University of California, San Diego, La Jolla CA 92093, USA

Full list of author information is available at the end of the article
}

Published: 18 July 2011

\section{Reference}

1. Buibas $M$, Silva $\mathrm{G}$ : A framework for simulating and estimating the state and functional topology of complex dynamic geometric networks. Neural Comput 2011, 23(1):183-214.

doi:10.1186/1471-2202-12-S1-P299

Cite this article as: Maranhao et al:: Assessing predictive capability of neuronal network models by computing Lyapunov exponents. BMC Neuroscience 2011 12(Suppl 1):P299.
Submit your next manuscript to BioMed Central and take full advantage of:

- Convenient online submission

- Thorough peer review

- No space constraints or color figure charges

- Immediate publication on acceptance

- Inclusion in PubMed, CAS, Scopus and Google Scholar

- Research which is freely available for redistribution

Submit your manuscript at www.biomedcentral.com/submit
() Bïomed Central
C Biomed Central

(c) 2011 Maranhao et al; licensee BioMed Central Ltd. This is an open access article distributed under the terms of the Creative Commons Attribution License (http://creativecommons.org/licenses/by/2.0), which permits unrestricted use, distribution, and reproduction in any medium, provided the original work is properly cited. 